\title{
Allergic sensitization in Canadian chronic rhinosinusitis patients
}

Brett J Green ${ }^{1}$, Donald H Beezhold ${ }^{1 *}$, Zane Gallinger ${ }^{2}$, Carly S Barron², Rochelle Melvin², Toni A Bledsoe ${ }^{1}$, Michael L Kashon ${ }^{3}$ and Gordon L Sussman ${ }^{2}$

\begin{abstract}
Background: Chronic rhinosinusitis (CRS) is a societal burden and cause of morbidity in Canada; however, the prevalence of allergic sensitization in Canadian CRS patients has remained poorly characterized.

Objective: In this study, we used skin prick test (SPT) and specific immunoglobulin E (slgE) and G (slgG) titers to regionally relevant allergen sources in order to determine whether allergic sensitization is more prevalent in CRS patients compared to chronic idiopathic urticaria (CIU) control patients.

Methods: One hundred and fifty eight subjects (19-70 years of age) were recruited into the study. 101 subjects had a confirmed diagnostic history of CRS and 57 subjects with a clinical diagnosis of CIU were recruited as controls. Enrolled subjects underwent SPT to a panel of perennial and seasonal allergens and slgE titers were quantified to selected environmental allergen mixes (grass, mold, and tree species) using Phadia ImmunoCAP. slgG was additionally quantified to Alternaria alternata, Aspergillus versicolor, Cladosporium herbarum, and Stachybotrys atra. Differences between CRS and control CIU patient SPT and serological data were examined by chi-squared analysis and analysis of variance.
\end{abstract}

Results: Reactivity to at least one SPT extract occurred in $73 \%$ of CRS patients. Positive SPT reactivity to A. alternata (odds ratio (OR): 4.34, 95\% confidence interval: 1.57, 12.02), cat (OR: 3.23,95\% Cl: 1.16, 9.02), and ragweed (OR: 2.31, $95 \%$ Cl: $1.02,5.19)$ extracts were more prevalent in patients with CRS $(p<0.05)$. Although dust mite and timothy grass sensitization approached statistical significance in the chi-squared analysis of SPT data, other common perennial and seasonal allergens were not associated with CRS. No statistically significant differences were observed between mean slgE and slgG titers in CRS and control patients.

Conclusions: This study supports previous data that suggests A. alternata sensitization is associated with CRS; however, these findings additionally highlight the contribution of other regionally important allergens including cat and ragweed.

Keywords: Allergic rhinitis, Allergic sensitization, Chronic rhinosinusitis, Perennial allergens

\section{Background}

Chronic rhinosinusitis (CRS) is characterized by inflammation of the nasal mucosa and one or more paranasal sinuses for temporal intervals extending 8-12 weeks [1-3]. In Canada, CRS is an increasing public health burden and accounted for approximately 3 million dispensed prescriptions in 2006 [4,5]. Several Canadian epidemiological

\footnotetext{
* Correspondence: zec1@cdc.gov

'Allergy and Clinical Immunology Branch, Health Effects Laboratory Division, National Institute for Occupational Safety and Health, Centers for Disease Control and Prevention, 1095 Willowdale Road, M/S L-4020, 26505 Morgantown, WV, USA

Full list of author information is available at the end of the article
}

surveys have reported the prevalence of CRS to affect approximately $5 \%$ of the general population [5,6]. In those studies, the prevalence of CRS was higher in women compared to men and eastern provinces had the highest prevalence of CRS $[5,6]$. In Canada, like the United States, CRS causes significant morbidity and reduced workplace productivity [2,5,7]. In the National Population Health Survey, Canadian survey participants that were identified with CRS had a self-perceived health status comparable to participants with other chronic conditions such as cancer, arthritis, asthma and inflammatory bowel disease [5]. A reduction in the mental health of 
survey participants with CRS was also reported and associated with a higher prevalence of depression, antidepressant use, and number of visits to mental health professionals [5]. These results highlight the emerging societal burden of CRS; however, fewer studies have characterized the allergic sensitizations associated with cases of CRS in Canada.

Studies of CRS etiology have shown that a progressive accumulation of mucus can result in remodeling and obstruction of the sinus ostia, bone erosion, facial pain, swelling, and can co-occur with or without polyp formation [1]. Although CRS may have an infectious or non-infectious basis $[1,8]$, allergic sensitization has been suggested in several studies as an important contributing factor to the underlying pathology [3,6,9-11]. Total IgE levels have been shown to correlate with the extent of CRS disease on sinus CT [12]. Inflammation, swelling and decreased mucociliary clearance associated with allergic rhinitis and eosinophilic inflammation have been postulated to enhance paranasal sinus ostia destruction $[6,9,10]$. This pathology may increase the risk of CRS development in sensitized patients but to date, the role of allergens and allergic sensitization remains uncharacterized and requires further clinical evaluation.

The coexistence of allergic rhinitis and CRS has been previously reported in the literature $[9,10,13,14]$ including in a Canadian study [6]. The prevalence of allergic sensitization has been reported to be as high as $84 \%$ in patients with CRS $[9,13]$ and a major subset of this patient group can be sensitized to more than one allergen [9]. Perennial allergen sensitization is more prevalent in CRS patients [14] with dust mite and mold allergens among the most frequently reported sensitizing sources $[9,14]$. The role of fungi in CRS has been the focus of many research studies as these microbial contaminants are commonly recovered from eosinophilic/allergic mucin. The association with fungi has been controversial but is sometimes described as mediating host immune reactions leading to the development of CRS $[8,15]$. Despite these experimental findings, the contribution of fungi and other perennial allergens to CRS in Canada has remained poorly characterized.

In this study, we document the prevalence of allergic sensitization to a selection of regionally prevalent perennial and seasonal allergen sources in a cohort of Canadian CRS patients. In addition, we compare the prevalence of allergic sensitization to a wider panel of fungi implicated in CRS. The identification of allergic sensitization to regionally prevalent allergens may be an additional diagnostic marker of CRS in clinical populations.

\section{Materials and methods Human subjects}

One hundred and fifty eight study participants from the Toronto metropolitan area (19-70 years of age) were recruited into the study. One hundred and one subjects were diagnosed with a history of CRS and 57 subjects were recruited as controls with chronic spontaneous urticaria (CIU). These study participant numbers were not based on a sample size calculation. CRS was physician diagnosed by physical exam based on the following symptomology: sinus congestion or fullness; facial pain, pressure or fullness; nasal obstruction or blockage; purulent anterior or posterior nasal drainage; and decrease sense of smell [16]. All CRS patients had endoscopy and CT scans confirming diagnosis of CRS. CIU is generally considered a non-IgE mediated disease and physician diagnosed patients were recruited to the control population as a way to control for confounding variables. When possible, consecutive patients presenting to the clinic were recruited to this study.

Enrolled subjects underwent skin prick testing (SPT) and were asked to provide a blood sample by venipuncture $(20 \mathrm{~mL})$ for serological analysis of specific immunoglobulin E (sIgE) and G (sIgG). Human serum was separated in vitro from the collected blood samples and then transferred to the National Institute for Occupational Safety and Health (NIOSH) and stored at $-80^{\circ} \mathrm{C}$ until serological analysis. This study was approved by the NIOSH Human Subject Review Board (05-HELD-04XP) and the Ontario Institutional Review Board Services. Informed consent was obtained from all participants.

\section{Skin prick testing}

The panel of SPT extracts comprised a variety of perennial (cat, dog, dust mite, cockroach and mouse), grass/weed (june, orchard, sweet timothy, cocklebur and ragweed), tree (ash, black birch, elm, maple, oak, pine, poplar and willow) and fungal allergens (Alternaria alternata, Aspergillus flavus, Cephalosporium, Cephalothecium, Fusarium, Helminthosporium, Hormodendrum, Monilia sitophila, Mucor, Penicillium, Phoma, and Rhizopus) from ALK (Hørsholm, Denmark). SPTs were performed by placing a drop of test solution on the skin and pricking the epidermis beneath the drop with a disposable plastic lancet (J.N. Eberle GmbH Hochfeldrasse 6-8 D-86830 Schwabmuenchen, Germany). SPT sites were wiped clean and after fifteen minutes, the wheal and flare reactions were outlined and the diameters measured. Histamine $(10 \mathrm{mg} / \mathrm{mL})$ was used as a positive control and diluent (HSA in 50\% glycerol) was used as a negative control. A positive reaction was characterized as $3 \mathrm{~mm}$ or greater than that of the negative control.

\section{Serological analysis}

Serological quantification of sIgE and sIgG titers was conducted by fluoroenzyme immunoassay using a Phadia ImmunoCAP 100 (Phadia AB, Uppsala, Sweden). sIgE was quantified to selected environmental allergens using a sIgE 
multiple allergen mix to grass (gx1), molds (mx2), and trees (tx1). The grass mix (gx1) was comprised of Dactylis glomerata (g3), Festuca elatior (g4), Lolium perenne (g5), Phleum pratense (g6), and Poa pratense (g8). The mold mix (mx2) was comprised of Penicillium chrysogenum (m1), Cladosporium herbarum (m2), Aspergillus fumigatus (m3), Candida albicans (m5), A. alternata (m6), and
Setomelanomma rostrata $(\mathrm{m} 8)$. The tree pollen mix (tx1) was comprised of Acer negundo (t1), Betula verrucosa (t3), Quercus alba (t7), Ulmus americana (t8), and Juglans californica (t10). sIgE was considered detectable when 65 allergen specific units $(\mathrm{kUA} / \mathrm{L})$ were exceeded. sIgG titers were also measured using ImmunoCAP for a 4-mold panel: C. herbarum (Gm2), A. alternata (Gm6),

Table 1 Chi-squared analyses of skin prick test $(\mathrm{SPT})$ reactivity among CRS patients $(\mathrm{n}=99)$ and control patients ( $n=44)$

\begin{tabular}{|c|c|c|c|c|c|c|c|c|c|c|}
\hline \multirow{2}{*}{ SPT extract } & \multicolumn{3}{|c|}{ CRS positive $^{\dagger}$} & \multicolumn{3}{|c|}{ CRS negative $^{\neq}$} & \multirow{2}{*}{$\begin{array}{l}\text { Odds } \\
\text { ratio }\end{array}$} & \multirow{2}{*}{$\begin{array}{l}\text { Lower } \\
95 \% \mathrm{Cl}\end{array}$} & \multirow{2}{*}{$\begin{array}{l}\text { Upper } \\
95 \% \mathrm{Cl}\end{array}$} & \multirow{2}{*}{$p$ value } \\
\hline & $n$ & n pos & \%pos & $n$ & n pos & \%pos & & & & \\
\hline \multicolumn{11}{|l|}{ Perennial } \\
\hline Cat & 99 & 29 & 29.29 & 44 & 5 & 11.36 & 3.23 & 1.16 & 9.02 & 0.02 \\
\hline Dust Mite & 99 & 29 & 29.29 & 44 & 7 & 15.91 & 2.19 & 0.88 & 5.48 & 0.09 \\
\hline Dog & 99 & 13 & 13.13 & 44 & 2 & 4.55 & 3.17 & 0.68 & 14.72 & 0.15 \\
\hline Cockroach & 99 & 0 & 0 & 44 & 0 & 0 & $\mathrm{nc}$ & $\mathrm{nc}$ & $\mathrm{nc}$ & $\mathrm{nc}$ \\
\hline Mouse & 99 & 0 & 0 & 44 & 0 & 0 & $\mathrm{nc}$ & $\mathrm{nc}$ & $\mathrm{nc}$ & $\mathrm{nc}$ \\
\hline \multicolumn{11}{|l|}{ Seasonal } \\
\hline Ragweed & 99 & 40 & 40.40 & 44 & 10 & 22.73 & 2.31 & 1.02 & 5.19 & 0.05 \\
\hline June & 99 & 30 & 30.30 & 19 & 4 & 21.05 & 1.63 & 0.50 & 5.32 & 0.58 \\
\hline Black Birch & 99 & 21 & 21.21 & 44 & 6 & 13.64 & 1.71 & 0.64 & 4.57 & 0.35 \\
\hline Timothy & 99 & 19 & 19.19 & 43 & 3 & 6.98 & 3.16 & 0.88 & 11.34 & 0.08 \\
\hline Orchard & 99 & 19 & 19.19 & 19 & 3 & 15.79 & 1.26 & 0.33 & 4.79 & 1 \\
\hline Sweet & 99 & 19 & 19.19 & 19 & 2 & 10.53 & 2.02 & 0.43 & 9.49 & 0.52 \\
\hline Ash & 99 & 16 & 16.6 & 20 & 3 & 15 & 1.09 & 0.29 & 4.17 & 1 \\
\hline Cocklebur & 99 & 10 & 10.10 & 19 & 0 & 0 & 0.82 & 0.76 & 0.89 & 0.36 \\
\hline Maple & 99 & 9 & 9.09 & 20 & 0 & 0 & 0.82 & 0.75 & 0.89 & 0.35 \\
\hline Willow & 99 & 7 & 7.07 & 20 & 1 & 5.00 & 1.45 & 0.17 & 12.44 & 1.00 \\
\hline Oak & 99 & 7 & 7.07 & 20 & 0 & 0 & 0.82 & 0.75 & 0.89 & 0.59 \\
\hline Poplar & 99 & 5 & 5.05 & 20 & 1 & 5.00 & 1.01 & 0.11 & 9.15 & 1 \\
\hline Elm & 99 & 4 & 4.04 & 20 & 0 & 0 & 0.83 & 0.76 & 0.89 & 1 \\
\hline Pine & 99 & 2 & 2.02 & 20 & 1 & 5.00 & 0.39 & 0.03 & 4.54 & 0.43 \\
\hline \multicolumn{11}{|l|}{ Fungal } \\
\hline Alternaria alternata & 99 & 36 & 36.36 & 43 & 5 & 11.63 & 4.34 & 1.57 & 12.02 & 0.003 \\
\hline Hormodendrum & 99 & 14 & 14.14 & 20 & 0 & 0 & 0.81 & 0.74 & 0.89 & 0.12 \\
\hline Cephalosporium & 99 & 5 & 5.05 & 20 & 0 & 0 & 0.82 & 0.76 & 0.89 & 0.59 \\
\hline Phoma & 99 & 5 & 5.05 & 20 & 0 & 0 & 0.82 & 0.76 & 0.89 & 0.59 \\
\hline Aspergillus flavus & 99 & 4 & 4.04 & 20 & 0 & 0 & 0.83 & 0.76 & 0.89 & 1 \\
\hline Fusarium & 99 & 4 & 4.04 & 20 & 0 & 0 & 0.83 & 0.76 & 0.89 & 1 \\
\hline Penicillium & 99 & 3 & 3.03 & 20 & 0 & 0 & 0.82 & 0.76 & 0.89 & 1 \\
\hline Cephalothecium & 99 & 2 & 2.02 & 20 & 0 & 0 & 0.82 & 0.76 & 0.90 & 1 \\
\hline Helminthosporium & 99 & 2 & 2.02 & 20 & 0 & 0 & 0.83 & 0.76 & 0.90 & 1 \\
\hline Rhizopus & 99 & 1 & 1.01 & 20 & 0 & 0 & 0.83 & 0.77 & 0.90 & 1 \\
\hline Mucor & 99 & 1 & 1.01 & 20 & 0 & 0 & 0.83 & 0.77 & 0.9 & 1 \\
\hline Monilia & 99 & 0 & 0 & 20 & 0 & 0 & $\mathrm{nc}$ & $\mathrm{nc}$ & $\mathrm{nc}$ & $\mathrm{nc}$ \\
\hline
\end{tabular}

Two CRS patients ( + ) and 13 control subjects (\$) were not evaluated by SPT. 
Stachybotrys atra (RGm24), and Aspergillus versicolor (RGm25). sIgG $<0.02 \mathrm{mg} / \mathrm{L}$ was considered undetectable as previously described [17].

\section{Statistical analysis}

The data analysis for this manuscript was generated using SAS/STAT software, Version 9.1 of the SAS System for Windows (SAS Institute Inc., Cary, NC, USA). Chi-square analysis was performed using Fishers Exact option to determine if the proportion of positive SPT's were different between groups. Antibody levels were compared using Analysis of Variance. All differences were considered significant at $\mathrm{p}<0.05$.

\section{Results}

Of the 158 study participants recruited into the study, 101 had a confirmed clinical history of CRS and 57 control subjects had a clinical history of CIU but not CRS. In the CRS group, there were 59 females and 42 males. The age range was $19-70$ and the mean age was 44.5 . In the control group, there were 28 females and 29 males with an age range 33-61 and the mean age was 47. A total of 31 SPT antigen extracts were tested and 72 out of 99 (73\%) CRS patients and 14 out of 44 (32\%) CIU control patients reacted to at least one SPT extract (data not shown).

The SPT extracts most likely to elicit a positive SPT response in the CRS population were ragweed (40\%), $A$. alternata (36\%), cat (29\%), dust mite (29\%), and June grass (30\%; Table 1). In the control population, ragweed (22\%), cat (11\%), June grass (21\%), and dust mite (16\%) extracts were the most common (Table 1). The SPT reactivity to the $A$. alternata extract was 3 fold higher in CRS compared to the control population. In the serological analysis, sIgE for the grass mix (21\%) and tree mix (24\%) was lower in CRS compared to control patients; however, there was a greater prevalence of fungal positive patients in CRS (21\%) compared to the control population $(16 \%)$ but this was not statistically significant (Table 2).

In the chi-squared analysis, positive SPT responses to A. alternata were more prevalent in patients with CRS compared to controls (odds ratio (OR): 4.34, 95\% confidence interval: $1.57,12.02$; Table 1). Sensitization to other perennial and seasonal SPT extracts including cat (OR:
3.23, 95\% CI: $1.16,9.02)$ and ragweed (OR: $2.31,95 \%$ CI: $1.02,5.19)$ was additionally identified to be more prevalent in the CRS group compared to the control group (Table 1). An elevated OR (1.4) was also observed following the analysis of IgE ImmunoCAP mold mix serological data; however, this was not statistically significant (Table 2). Differences between CRS and control patients were observed for other perennial and seasonal allergen sources including dog (OR: 3.17, 95\% CI: 0.68, 14.72), dust mite (OR: $2.19,95 \% \mathrm{CI}: 0.88,5.48$ ), and timothy grass (OR: 3.16, 95\% CI: 0.88, 11.34); however, these differences did not reach statistical significance and that may be due to the small sample size (Table 1). No other statistically significant differences were identified between the other allergen extracts tested in the SPT and serological analysis (Table 2).

In the ANOVA analysis of sIgE, the mean allergen specific units $(\mathrm{kUA} / \mathrm{L})$ measured for CRS and CIU control patients did not vary for grass $(\mathrm{p}=0.67)$, mold $(\mathrm{p}=0.34)$ or tree mix $(\mathrm{p}=0.46)$ ImmunoCAP antigens (Table 3$)$. Similarly, there were no statistically significant differences between mean sIgG titers $(\mathrm{mg} / \mathrm{mL})$ in CRS and control patients for C. herbarum $(\mathrm{p}=0.84)$, A. alternata $(\mathrm{p}=0.92), S$. atra $(\mathrm{p}=0.13)$, and A. versicolor $(\mathrm{p}=0.22$; Table 4).

\section{Discussion}

In this study, $73 \%$ of CRS patients had a positive SPT to at least one of the tested allergen extracts. Sensitization to A. alternata, cat and ragweed were the most prevalent sensitizations in CRS patients compared to the control population. Sensitization to dust mite or timothy grass was also noted but these results were not statistically significant. These results highlight the potential importance of allergic sensitization to A. alternata and other perennial or seasonal allergen sources in CRS patients.

The prevalence of CRS patients having at least one positive SPT (73\%) was comparable to results reported in a study that was located in close proximity (Cleveland, $\mathrm{OH})$ to Toronto [9]. The identification of increased prevalence of fungal allergy in CRS was also identified in Cleveland as well as in southern regions of the United States $[8,14,18]$ but not in Europe [19]. The serological results reported in the present study varied from previous

Table 2 Chi-squared analysis of human serum IgE reactivity to grass (gx1), mold (mx2), and tree (tx1) mix Phadia ImmunoCap antigens

\begin{tabular}{|c|c|c|c|c|c|c|c|c|c|c|}
\hline \multirow{2}{*}{$\begin{array}{c}\operatorname{lgE} \\
\text { ImmunoCap } \\
\text { Antigen* }\end{array}$} & \multicolumn{3}{|c|}{ CRS positive } & \multicolumn{3}{|c|}{ CRS negative } & \multirow{2}{*}{$\begin{array}{l}\text { Odds } \\
\text { ratio }\end{array}$} & \multirow{2}{*}{$\begin{array}{l}\text { Lower } \\
95 \% \mathrm{Cl}\end{array}$} & \multirow{2}{*}{$\begin{array}{l}\text { Upper } \\
95 \% \mathrm{Cl}\end{array}$} & \multirow[b]{2}{*}{$p$ value } \\
\hline & $\mathrm{n}$ & $\mathrm{n}$ pos & \%pos & $\mathrm{n}$ & n pos & \%pos & & & & \\
\hline Grass Mix (gx1) & 101 & 21 & 20.79 & 57 & 13 & 22.81 & 0.89 & 0.41 & 1.95 & 0.84 \\
\hline Mold Mix (m×2) & 101 & 21 & 20.79 & 57 & 9 & 15.79 & 1.40 & 0.59 & 3.31 & 0.53 \\
\hline Tree Mix (tx1) & 101 & 24 & 23.76 & 57 & 15 & 26.32 & 0.87 & 0.41 & 1.84 & 0.84 \\
\hline
\end{tabular}

*Serum IgE titers $>65 \mathrm{kUA} / \mathrm{L}$ were interpreted as positive to the tested Phadia ImmunoCap antigen. 
Table 3 Analysis of variance of the mean allergen specific units (kUA/L) measured for CRS $(n=101)$ and control patients $(n=57)$

\begin{tabular}{|c|c|c|c|c|c|c|}
\hline \multirow{2}{*}{$\begin{array}{c}\lg \mathrm{E} \\
\text { ImmunoCap } \\
\text { Antigen }\end{array}$} & \multicolumn{2}{|c|}{ CRS Positive } & \multicolumn{2}{|c|}{ CRS Negative } & \multirow[b]{2}{*}{ F value } & \multirow[b]{2}{*}{$P$ value } \\
\hline & $\begin{array}{c}\text { Mean allergen specific } \\
\text { units (kUA/L) }\end{array}$ & Standard error & $\begin{array}{c}\text { Mean allergen specific } \\
\text { units (kUA/L) }\end{array}$ & Standard error & & \\
\hline Grass Mix (GX1) & 397.37 & 166.59 & 517.56 & 221.76 & 0.19 & 0.67 \\
\hline Mold Mix (MX2) & 103.03 & 65.57 & 206.81 & 87.28 & 0.90 & 0.34 \\
\hline Tree Mix (TX1) & 322.45 & 101.28 & 198.76 & 134.81 & 0.54 & 0.46 \\
\hline
\end{tabular}

studies reporting up to a 5 fold increase in IgG titers as well as increases in $\mathrm{IgE}^{+}$cells (mast, plasma cells) in CRS patients [20,21]. The lack of concordance between SPT and serological studies in CRS patients may be due to increased sensitivity of SPT but also the variability of allergen extracts, as well as concurrent exposure of the subjects to antigens derived from a varying spectrum of perennial and seasonal allergen sources (tree, grass, insect, and fungal) [9]. Allergic sensitization to staphylococcal and streptococcal toxins has been found to be as high as $78 \%$ in CRS patients [22]. While these factors were not evaluated in the present study, they could also influence the pathology and prevalence of sensitization in CRS patients. Taking these limitations into consideration, the results of the present study suggest that evidence of allergic sensitization, in particular fungal hypersensitivity, could potentially be used as diagnostic criteria for CRS $[8,18]$. Currently, the Canadian clinical practice guidelines for CRS recognize allergy testing in cases of CRS but the guidelines do not recognize specific allergens [4].

In the present study, $36 \%$ of the CRS study participants were sensitized to $A$. alternata. These SPT results are comparable to other studies that have identified sensitization to Alternaria in CRS patients [20]. A. alternata has been previously implicated in cases of CRS in the United States [20] and it is among the most ubiquitous phyloplane fungal species in Toronto [23,24]. The presence of $A$. alternata conidia in the upper respiratory tract has been demonstrated in microscopic and immunologic studies of allergic mucin derived from CRS subjects [25-27]. In vitro studies have also shown that $A$. alternata extracts induce the recruitment of eosinophils, induce interferon-y, IL-5 and IL-13 in peripheral blood mononuclear cells [20,28]; and regulates the expression of surfactant protein D and LL-37 in fungal sensitized CRS patients $[29,30]$. It has been hypothesized that allergens released from Alternaria conidia and germinating conidia may have a functional role in CRS but this has remained controversial and is the subject of continued research $[8,31]$.

Sensitization to cat and ragweed were additionally identified as prevalent sensitizations in the present study, and sensitization to these allergens has been previously reported in a CRS study in Washington D.C. [32]. Cat allergy is an important source of perennial allergen in inner city environments. Interestingly, Canadian aerobiological surveys have shown that the highest concentration of ragweed pollen occur in southern Ontario [33].

Our results deviate from previous studies that have identified dust mite to be an important perennial allergen associated with CRS $[9,13,19,34]$. Gutman and colleagues identified $73 \%$ of CRS patients in Cleveland to be sensitized to dust mite [9]. A study of 200 patients in San Francisco who had undergone functional endoscopic sinus surgery for chronic or recurrent rhinosinusitis showed that $22 \%$ were sensitized to house dust mite [13]. Freudenberger et al. [34] also identified 68\% of CRS patients in New York to exhibit a positive immediate skin test reaction to dust mite extract. Although dust mite sensitization can be as high as $60 \%$ in Toronto [35], the prevalence of sensitization to dust mite only approached $30 \%$ in the present study and was not more prevalent in patients with CRS. To date, the role of seasonal and perennial allergy in CRS requires further evaluation; however, the results of this study suggest that in addition to Alternaria, cat and ragweed allergens may additionally contribute to swelling and blockage of sinus ostia leading to mucous buildup, secondary infection, and the development of CRS [4].

Table 4 Analysis of variance of the mean IgG titer $(\mathrm{mg} / \mathrm{mL})$ measured for CRS $(n=101)$ and control patients $(n=57)$

\begin{tabular}{|c|c|c|c|c|c|c|}
\hline \multirow{2}{*}{ IgG ImmunoCap Antigen } & \multicolumn{2}{|c|}{ CRS Positive } & \multicolumn{2}{|c|}{ CRS Negative } & \multirow{2}{*}{ F value } & \multirow{2}{*}{$P$ value } \\
\hline & Mean IgG $(\mathrm{mg} / \mathrm{mL})$ & Standard error & Mean IgG $(\mathrm{mg} / \mathrm{mL})$ & Standard error & & \\
\hline Cladosporium herbarum (GM2) & 31.18 & 3.47 & 32.33 & 4.62 & 0.04 & 0.84 \\
\hline Alternaria alternata (GM6) & 5.05 & 0.42 & 4.98 & 0.56 & 0.01 & 0.92 \\
\hline Stachybotrys atra (RGM24) & 4.75 & 0.39 & 3.76 & 0.51 & 2.36 & 0.13 \\
\hline Aspergillus versicolor (RGM25) & 23.76 & 2.66 & 18.54 & 3.41 & 1.53 & 0.22 \\
\hline
\end{tabular}


There were several limiting factors associated with the design of this study that should be considered when interpreting these results. The association of other seasonal and perennial allergens to CRS such as dust mite, dog and timothy grass may have been identified if a larger number of study participants and controls were recruited into the study. Selection and recruitment of patients included CRS patients with and without nasal polyps and allergic fungal sinusitis which may have resulted in the over estimation of allergic sensitization in this population of Canadian CRS patients $[10,11,36]$. However, our objective was to study the overall prevalence of allergy sensitization in CRS. Geographic variability in CRS and allergic sensitization are also variables that may have influenced the results of this study [5,6]. Surveys of CRS in Canada have shown a greater prevalence of CRS in eastern provinces, in particular Nova Scotia [5]. We hypothesize that the allergen burden in Nova Scotia may differ to the Toronto metropolitan environment due to a varying spectrum of tree, grass, weed, insect and mold allergens and as a result, the profile of allergic sensitization may vary substantially. Future studies should include larger patient numbers and utilize a wider panel of perennial and seasonal allergens that reflect the allergen burden of the local study environment.

\section{Conclusions}

In conclusion, the results of this study demonstrate a general association between CRS and allergic sensitization. In the Toronto metropolitan area, A. alternata was prominent but cat and ragweed allergens were also associated with CRS. Taken together, these results suggest exposure to regionally specific allergens may drive a process resulting in CRS in some patients, perhaps with a genetic predisposition or epidermal barrier dysfunction. Future studies should be designed in other regions of Canada to identify and characterize the specific sensitization profiles of CRS patients.

\section{Competing interests}

The authors declare no conflict of interest or competing interests.

\footnotetext{
Authors' contributions

BJG is a co-investigator with input on study design, interpreted statistical results, and prepared the manuscript. DHB is a co-investigator with input on study design and implementation, and assisted in the preparation and review of the manuscript. ZG enrolled patients, conducted regulatory work, and assisted in the collection of data, CSB conducted data analysis, reviewed patient charts, and reviewed the manuscript. RM recruited patients, conducted data analysis, reviewed patient charts, and reviewed the manuscript. TAB conducted the Phadia ImmunCAP serological analysis and reviewed the manuscript. MLK conducted the statistical analysis, interpreted and discussed results, and reviewed the manuscript. GLS is the principle investigator and contributed to the enrolment of patients, data capture and processing and has reviewed and commented on various drafts of the manuscript. All authors have read and approved the final manuscript.
}

\section{Acknowledgements}

The findings and the conclusions in this report are those of the authors and do not necessarily represent the views of the National Institute for Occupational Safety and Health. This study was supported in part by an interagency agreement with NIEHS IAA\#AES 12007-00100000.

\section{Author details}

${ }^{1}$ Allergy and Clinical Immunology Branch, Health Effects Laboratory Division, National Institute for Occupational Safety and Health, Centers for Disease Control and Prevention, 1095 Willowdale Road, M/S L-4020, 26505 Morgantown, WV, USA. ${ }^{2}$ Gordon Sussman Clinical Research Inc., Allergy and Clinical Immunology, Toronto, Ontario, Canada. ${ }^{3}$ Biostatics and Epidemiology Branch, Health Effects Laboratory Division, National Institute for Occupational Safety and Health, Centers for Disease Control and Prevention, Morgantown, West Virginia, USA

Received: 23 December 2013 Accepted: 12 March 2014

Published: 25 March 2014

\section{References}

1. Dykewicz MS: 7. Rhinitis and sinusitis. J Allergy Clin Immunol 2003, 111:S520-S529.

2. Kaliner MA, Osguthorpe JD, Fireman P, Anon J, Georgitis J, Davis ML, Naclerio R, Kennedy D: Sinusitis: bench to bedside. Current findings, future directions. Otolaryngol Head Neck Surg 1997, 116:S1-S20.

3. Kilty S: Canadian guidelines for rhinosinusitis: practical tools for the busy clinician. BMC Ear Nose Throat Disord 2012, 12:1.

4. Desrosiers M, Evans GA, Keith PK, Wright ED, Kaplan A, Bouchard J, Ciavarella A, Doyle PW, Javer AR, Leith ES, Mukherji A, Schellenberg RR, Small P, Witterick IJ: Canadian clinical practice guidelines for acute and chronic rhinosinusitis. Allergy Asthma Clin Immunol 2011, 7:2.

5. Macdonald Kl, McNally JD, Massoud E: The health and resource utilization of Canadians with chronic rhinosinusitis. Laryngoscope 2009, 119:184-189.

6. Chen Y, Dales R, Lin M: The Epidemiology of Chronic Rhinosinusitis in Canadians. Laryngoscope 2003, 113:1199-1205.

7. Ray NF, Baraniuk JN, Thamer M, Rinehart CS, Gergen PJ, Kaliner M, Josephs S, Pung YH: Healthcare expenditures for sinusitis in 1996: contributions of asthma, rhinitis, and other airway disorders. J Allergy Clin Immuno 1999, 103:408-414

8. Pakdaman MN, Corry DB, Luong A: Fungi Linking the Pathophysiology of Chronic Rhinosinusitis with Nasal Polyps and Allergic Asthma. Immunol Invest 2011, 40:767-785.

9. Gutman M, Torres A, Keen KJ, Houser SM: Prevalence of Allergy in Patients with Chronic Rhinosinusitis. Otolaryngol Head Neck Surg 2004, 130:545-552.

10. Fokkens $\mathrm{W}$, Lund $\mathrm{V}$, Mullol J: European position paper on rhinosinusitis and nasal polyps. Rhinol Supp/ 2007, 2007:1-136.

11. Pant $\mathrm{H}$, Ferguson BJ, Macardle PJ: The role of allergy in rhinosinusitis. Curr Opin Otolaryngol Head Neck Surg 2009, 17:232-238.

12. Lal D, Baroody FM, Weitzel EK, DeTineo M, Naclerio RM: Total IgE levels do not change 1 year after endoscopic sinus surgery in patients with chronic rhinosinusitis. Int Arch Allergy Immunol 2006, 139:146-148.

13. Emanuel IA, Shah SB: Chronic rhinosinusitis: Allergy and sinus computed tomography relationships. Otolaryngol Head Neck Surg 2000, 123:687-691

14. Huang SW: The risk of sinusitis in children with allergic rhinitis. Allergy Asthma Proc 2000, 21:85-88.

15. Fokkens WJ, Van Drunen C, Georgalas C, Ebbens F: Role of fungi in pathogenesis of chronic rhinosinusitis: the hypothesis rejected. Curr Opin Otolaryngol Head Neck Surg 2012, 20:19-23.

16. Kaplan A: Canadian guidelines for chronic rhinosinusitis: Clinical summary. Can Fam Physician 2013, 59:1275-1281-e1528-1234.

17. Green BJ, Cummings KJ, Rittenour WR, Hettick JM, Bledsoe TA, Blachere FM, Siegel PD, Gaughan DM, Kullman GJ, Kreiss K, Cox-Ganser J, Beezhold DH: Occupational sensitization to soy allergens in workers at a processing facility. Clin Exp Allergy 2011, 41:1022-1030.

18. Schubert MS: Allergic fungal sinusitis: pathophysiology, diagnosis and management. Med Mycol 2009, 47(Suppl 1):S324-S330.

19. Gawlik R: Mold sensitization in chronic rhinosinusitis patients. World Allergy Organ J 2012, 5:S96.

20. Shin SH, Ponikau JU, Sherris DA, Congdon D, Frigas E, Homburger HA Swanson MC, Gleich GJ, Kita H: Chronic rhinosinusitis: an enhanced 
immune response to ubiquitous airborne fungi. J Allergy Clin Immunol 2004, 114:1369-1375.

21. Carney AS, Tan LW, Adams D, Varelias A, Ooi EH, Wormald PJ: Th2 immunological inflammation in allergic fungal sinusitis, nonallergic eosinophilic fungal sinusitis, and chronic rhinosinusitis. Am J Rhinol 2006, 20:145-149.

22. Tripathi A, Conley DB, Grammer LC, Ditto AM, Lowery MM, Seiberling KA, Yarnold PA, Zeifer B, Kern RC: Immunoglobulin E to Staphylococcal and Streptococcal Toxins in Patients with Chronic Sinusitis/Nasal Polyposis. Laryngoscope 2004, 114:1822-1826.

23. Fitzgerald JD, Fischer J, Doenne AE: The seasonal incidence of atmospheric mould spores in Toronto (April 1953-April 1954). Can Med Assoc J 1955, 72:700-701.

24. Collins-Williams C, Kuo HK, Garey DN, Davidson S, Collins-Williams D, Fitch M, Fischer JB: Atmospheric mold counts in Toronto, Canada, 1971. Ann Allergy 1973, 31:69-71.

25. Guo C, Ghadersohi S, Kephart GM, Laine RA, Sherris DA, Kita H, Ponikau JU: Improving the detection of fungi in eosinophilic mucin: seeing what we could not see before. Otolaryngol Head Neck Surg 2012, 147:943-949.

26. Ponikau JU, Sherris DA, Kern EB, Homburger HA, Frigas E, Gaffey TA, Roberts GD: The diagnosis and incidence of allergic fungal sinusitis. Mayo Clin Proc 1999, 74:877-884.

27. Taylor MJ, Ponikau JU, Sherris DA, Kern EB, Gaffey TA, Kephart G, Kita H: Detection of fungal organisms in eosinophilic mucin using a fluoresceinlabeled chitin-specific binding protein. Otolaryngol Head Neck Surg 2002, 127:377-383.

28. Ponikau JU, Sherris DA, Kern EB: Immunologic response to fungus is not universally associated with chronic rhinosinusitis. Otolaryngol Head Neck Surg 2010, 143:607-610.

29. Ooi EH, Wormald PJ, Carney AS, James CL, Tan LW: Fungal allergens induce cathelicidin LL-37 expression in chronic rhinosinusitis patients in a nasal explant model. Am J Rhinol 2007, 21:367-372.

30. Ooi EH, Wormald PJ, Carney AS, James CL, Tan LW: Surfactant protein d expression in chronic rhinosinusitis patients and immune responses in vitro to Aspergillus and alternaria in a nasal explant model. Laryngoscope 2007, 117:51-57.

31. Montone KT: Role of fungi in the pathophysiology of chronic rhinosinusitis: an update. Curr Allergy Asthma Rep 2013, 13:224-228.

32. McNally PA, White MV, Kaliner MA: Sinusitis in an allergist's office: analysis of 200 consecutive cases. Allergy Asthma Proc 1997, 18:169-175.

33. Bassett IJ: Surveys of air-borne ragweed pollen in Canada with particular reference to sites in Ontario. Can J Plant Sci 1959, 39:491-497.

34. Freudenberger T, Grizzanti JN, Rosenstreich DL: Natural immunity to dust mites in patients with chronic rhinosinusitis. J Allergy Clin Immunol 1988, 82:855-862

35. Huss K, Adkinson NF Jr, Eggleston PA, Dawson C, Van Natta ML, Hamilton RG: House dust mite and cockroach exposure are strong risk factors for positive allergy skin test responses in the Childhood Asthma Management Program. J Allergy Clin Immunol 2001, 107:48-54.

36. Pant $\mathrm{H}$, Ferguson B, Hughes A, Schembri M: Confounding factors in rhinological research. Curr Opin Otolaryngol Head Neck Surg 2013, 21:282-292.

doi:10.1186/1710-1492-10-15

Cite this article as: Green et al: Allergic sensitization in Canadian chronic rhinosinusitis patients. Allergy, Asthma \& Clinical Immunology 2014 10:15

\section{Submit your next manuscript to BioMed Central and take full advantage of:}

- Convenient online submission

- Thorough peer review

- No space constraints or color figure charges

- Immediate publication on acceptance

- Inclusion in PubMed, CAS, Scopus and Google Scholar

- Research which is freely available for redistribution 